\title{
Claudia Mayorga
}

Universidade Federal de Minas Gerais

\author{
Alba Coura
}

Universidade Federal de Minas Gerais

Nerea Miralles

Universitat Autònoma de Barcelona

\author{
Vivane Martins Cunha
}

Universidade Federal de Minas Gerais

\section{As críticas ao gênero e a pluralização do feminismo: colonialismo, racismo e política heterossexual}

Resumo: Este artigo analisa a emergência de categorias específicas no feminismo colonialismo, racismo e política heterossexual -, focando em aspectos que interpelaram e seguem interpelando o conceito de gênero. Interessa aqui identificar quais contribuições essas categorias apresentam para se pensarem os sujeitos dos feminismos e a ação política feminista. Para tanto, propõe uma breve retomada histórica da noção de gênero no feminismo e analisa o pensamento de três autoras - Gloria Anzaldúa, Monique Wittig e Ochy Curiel - que, ao incluírem em suas análises sobre as mulheres e a sociedade a perspectiva do colonialismo, do racismo e da política heterossexual, buscaram explicitar os limites do gênero, entre eles, seus efeitos normativos, apontando para a necessidade de politização do próprio feminismo.

Palavras-chave: gênero; racismo; política heterossexual; colonialismo.

Copyright (c) 2013 by Revista Estudos Feministas.

\section{Introdução}

A categoria "gênero", desde que recebeu uma releitura por uma perspectiva de poder pelo feminismo, se tornou central na ação política e na teoria feministas, principalmente a partir da segunda metade do século XX. Nos anos subsequentes aos dos de 1970, as feministas se 
${ }^{1}$ Marlise MATOS, 2010.

\footnotetext{
2 O termo "heteronormatividade" tem estreita relação com a noção de sistema sexo/gênero, de Gayle Rubin (1975), e também com a discussão sobre heterossexualidade compulsória, de Adrienne Rich (1980). Neste momento utilizamos esse termo, mas, quando formos analisar o pensamento de Monique Wittig, apresentaremos a noção utilizada por essa pensadora feminista: política heterossexual e heterossexualidade.
}

apropriaram do gênero como elemento analítico da sociedade; vão caracterizá-lo como uma construção social e histórica de relações sociais desiguais estabelecidas entre homens e mulheres, o que acarreta a opressão das mulheres. Buscaram construir explicações para essa opressão e, para isso, irão propor leituras sobre a noção de gênero, sobre o sistema de opressão das mulheres (patriarcado, política sexual, sistema sexo-gênero etc.) e sobre a ação política feminista.

No nosso percurso, tanto como pesquisadoras quanto como mulheres participantes de diferentes áreas e movimentos relacionados com os feminismos, tem sido possível perceber e acompanhar, mais de 40 anos depois dos primeiros debates que marcaram a chamada segunda onda do feminismo, um outro momento do debate feminista. Se, por um lado, vivemos uma época em que a opressão das mulheres é um aspecto relativamente reconhecido nas sociedades ocidentais e há tentativas de construção de políticas de enfrentamento a essas desigualdades, o que faz com que algumas autoras identifiquem esse momento como a quarta onda do feminismo, ${ }^{1}$ críticas aos limites da noção de gênero e deslocamentos que vêm se produzindo com a entrada de diferentes leituras da opressão, dos novos conceitos, das rupturas epistemológicas e da emergência de vozes que tencionam as teorias e as ações feministas centradas na noção de gênero têm, há alguns anos, colocado questões sobre a possibilidade de uma unidade na ação política feminista, sobre o sujeito do feminismo e, consequentemente, sobre qual projeto de sociedade deve orientar essa ação.

Tais críticas foram e continuam sendo delineadas com base em distintas experiências de opressão de mulheres do Terceiro Mundo, negras, lésbicas, trabalhadoras que denunciaram que o feminismo que se fortaleceu a partir da segunda onda teve como uma de suas consequências a universalização de leituras da experiência de opressão e de emancipação de mulheres que desconsideraram e desqualificaram a pluralidade e a diversidade delas. Ao lançarem olhares críticos aos sistemas coloniais que marcaram a história de mulheres em diversos países, ao racismo, à heteronormatividade ${ }^{2}$ e às desigualdades de classe, outros feminismos emergiram indicando os limites, os efeitos normativos e os reducionismos da categoria "gênero" para a compreensão da opressão das mulheres, levando à problematização, inclusive, da própria noção de mulher. Um importante ponto de debate e tensão se refere à possibilidade de se construir uma agenda política comum.

Recentemente, em 2010, foi realizado o Seminário Internacional Direitos Sexuais, Feminismos e Lesbianidades: 
3 O Seminário Internacional Direitos Sexuais, Feminismos e Lesbianidades: Olhares Diversos foi realizado em Belo HorizonteMG, em novembro de 2010, pela Associação Lésbica de Minas (ALEM) e suas parcerias.

${ }^{4}$ Claudia MAYORGA e Marco Aurélio Máximo PRADO, 2010.
Olhares Diversos, ${ }^{3}$ no qual mulheres com experiências sociais e políticas distintas, como prostitutas, negras, lésbicas, heterossexuais, ateias e católicas, dos movimentos sociais, da universidade e do poder público etc., colocaram em pauta, não sem tensões, a discussão sobre a articulação das diversas demandas apresentadas por elas na construção de uma leitura sobre a opressão e, consequentemente, sobre sua ação política.

No Brasil, o movimento das trabalhadoras rurais, as jovens negras feministas, o movimento de lésbicas, a rede brasileira de prostitutas, o movimento de travestis e transexuais e tantos outros têm buscado, em suas organizações, enfrentar essas questões. Sabe-se que esses encontros representam espaços importantes de debate que reestruturam o imaginário de ações coletivas entre os segmentos dos movimentos sociais. No entanto, percebe-se que a construção de um horizonte comum ou a articulação de certas bandeiras não ocorre de forma linear e harmônica, e afirmar a necessidade de articulação de categorias sociais distintas exige cuida-dos analíticos e políticos. É importante considerar que essa proposta de articulação não pode prescindir de uma compreensão histórica e política das relações entre posições de desigualdade vivenciadas por e entre mulheres, como o lugar de fala de cada uma delas ou as relações de poder que marcam possibilidades e impossibilidades de apropriação de determinados recursos materiais e simbólicos. Assim, a proposta de articulação entre gênero, sexualidade, raça, lugar de origem etc. não pode correr o risco de se transformar em uma posição ingênua a partir da proposição de uma simples somatória de opressões, mas deve, de forma radical, reconhecer as tensões e os antagonismos que marcam a emergência dessas categorias dentro e fora do feminismo, ${ }^{4}$ bem como suas consequências na vida e na organização das mulheres.

Diante do que foi exposto, propomos a análise da emergência das categorias "colonialismo", "racismo" e "política heterossexual" no feminismo, focando nos aspectos que interpelaram e seguem interpelando o conceito de gênero. Sabemos que essas categorias não são exclusivas do feminismo, mas nos interessa aqui pensar sua emergência nesse campo político-teórico específico, identificando quais contribuições essas categorias apresentam para se pensarem os sujeitos dos feminismos e se é pertinente continuarmos trabalhando com essas noções de sujeito. Para tanto, apresentamos uma análise do pensamento de três autoras feministas - Gloria Anzaldúa, Monique Wittig e Ochy Curiel que, ao incluírem em suas análises sobre as mulheres e a sociedade a perspectiva do colonialismo, do racismo e da política heterossexual, explicitaram complexidades outras 
${ }^{5}$ Robert STOLLER, 1968. Para esse e outros autores, a distinção entre sexo e gênero objetiva diferenciar conceitualmente as características sexuais, os limites e as capacidades que elas implicam, além das características psíquicas, históricas e sociais das pessoas em sociedades onde o que se deve ser deve responder a uma bimodalidade em função do sexo ao qual se pertence. Stoller e outros constataram que não era possível classificar certos indivíduos como machos e fêmeas a partir da diferença sexual, por possuírem, de forma pouco marcada, os caracteres sexuais secundários ou por alterações de caráter cromossômico ou hormonal que afetavam a diferença sexual. Constataram também que algumas pessoas poderiam ajustar-se morfológica e funcionalmente a qualquer um dos dois sexos.

${ }^{6}$ Mary WOLLSTONECRAFT, 2001.

${ }^{7}$ Margareth MEAD, 2001.

${ }^{8}$ Simone de BEAUVOIR, 1972. para a luta feminista. O exercício crítico dessas autoras não se dá de forma isolada e individual e revela elementos de um momento em que tensões e antagonismos (re)emergiram e colocaram interrogações importantes para certo projeto feminista. Antes de passar para as autoras, destacaremos alguns aspectos sobre a história do gênero no feminismo.

\section{Gênero e sua relação com o político}

O termo "gênero" aparece inicialmente nos anos 1950/1960, nas ciências sociais dos Estados Unidos, mais especificamente na área da Psicologia. Nesse início, destacam-se alguns trabalhos, como o de Robert Stoller, Sex and Gender ${ }^{5}$ no qual o autor utiliza a oposição sexo/gênero para diferenciar a identidade sexual do sexo biológico.

A busca por um afastamento do determinismo biológico, uma das contribuições importantes da noção de gênero ao feminismo, já estava presente (mesmo sem o uso do termo) no pensamento de algumas autoras, como Mary Wollstonecraft, ${ }^{6}$ em seu livro A Vindication of the Rigths of Woman, Margaret Mead, ${ }^{7}$ em Sex and Temperament in Three Primitive Societies, e Simone de Beauvoir, ${ }^{8}$ em Le deuxième sexe.

Partindo de perguntas e preocupações distintas, elas questionaram a naturalização das diferenças sexuais e buscaram dessencializar os lugares sociais considerados femininos. Wollstonecraft fará uma forte crítica à razão iluminista, denunciando a exclusão das mulheres dos princípios da igualdade, liberdade e fraternidade através da naturalização e da essencialização da subordinação das mulheres e sua consequente exclusão política. Analisará o papel da educação na reprodução desse lugar para as mulheres e será na educação que vai identificar a possibilidade de transformação dessa situação de desigualdade, já que, a partir dela, valores como autonomia e emancipação poderiam ser disseminados. Mead, ao analisar a divisão sexual do trabalho e as estruturas de parentesco nas etnias arapesh, mundugumor e tchamboli, evidenciou que tanto homens como mulheres poderiam realizar atividades atribuídas de forma essencializada no mundo ocidental, a um ou outro. A autora vai defender a ideia de que as qualidades chamadas masculinas e femininas não estão baseadas nas determinações de diferenças sexuais, mas refletem condicionamentos culturais em sociedades diversas. Beauvoir, ao refletir sobre as experiências das mulheres e sobre o conhecimento construído sobre elas, também questionará a naturalização das diferenças entre homens e mulheres, posição defendida por meio de sua famosa frase: "Não se nasce mulher, tornase". Posteriormente, as contribuições dessas três autoras serão apropriadas de formas diversas. 
9 Uma das marcas da chamada primeira onda do feminismo, anterior às produções feministas da década de 1970, identificada também como marca importante do feminismo liberal, é a Declaração de Sêneca Falls, realizada em Nova York, em 1848. Foi um documento baseado na Declaração de Independência dos Estados Unidos, através do qual as sufragistas denunciaram as restrições, sobretudo no campo da política, às quais estavam submetidas as mulheres: além de não poderem votar, não poderiam comparecer às eleições nem ocupar cargos públicos. Além disso, não poderiam ter filiação a organizações políticas. Na Declaração, as mulheres se posicionavam contra a negação de seus direitos civis ou jurídicos e reivindicavam o direito à propriedade (entendido pelas feministas como o melhor meio de se alcançar autonomia), ao trabalho, ao voto, a ocupar cargos públicos e ao de se filiar a organizações políticas. A ideia presente era a de defender que ambos os sexos possuíam os mesmos direitos naturais e, portanto, ambos deveriam ter os mesmos direitos sociais (Alicia MIYARES, 1999). As mulheres burguesas passaram a ter mais preponderância no espaço público e as que tinham melhores condições financeiras começaram a frequentar instituições privadas de ensino e algumas se tornaram professoras ou enfermeiras, profissões que estavam de acordo com funções naturalizantes atribuídas às mulheres, como as da educação e do cuidado. Em um primeiro momento, a principal reivindicação das mulheres iluministas e liberais era o direito à educação e ao voto como forma de se obter cidadania. As feministas mais essencialistas argumentavam que o direito à educação iria capacitá-las para fornecer uma melhor educação para os próprios filhos. Além disso, algumas defendiam que o sufrágio feminino iria ocasionar uma dinâmica social mais satisfatória, visto que as mulheres eram naturalmente mais morais que os
Nos anos 1970, momento da segunda onda do feminismo, ${ }^{9}$ a antropóloga norte-americana Gayle Rubin, ${ }^{10}$ com seu texto "The Traffic in Women: Notes on the Political Economy of Sex", será uma das primeiras autoras a retomarem gênero como uma categoria políica para o feminismo, analisando como a subordinação das mulheres está baseada em relações sociais que organizam e produzem a sexualidade e o gênero. Ao se perguntar pelas razões da opressão sexual, ela vai identificar o sistema sexo/ gênero como aquele que institui normas de divisão de gênero e heterossexualidade obrigatória e coerções aos comportamentos masculinos e femininos. Nesse texto, a autora lança mão de uma perspectiva sobre o poder associada à análise da construção social e cultural de homens e mulheres: gênero é abordado por Rubin como sendo uma norma que institui e naturaliza a desigualdade entre homens e mulheres e a heterossexualidade obrigatória. Ao fazer essa proposta analíitica, politiza a noção de gênero, identificando-o como elemento de um sistema que institui a desigualdade. Suas reflexões contribuíram para a criação de um horizonte de transformação social no qual a diferença já não poderia ser compreendida como um ato casual da natureza, mas sim como uma ação de diferenciação em que a distinção é construída socialmente, impondo uma hierarquia do sexo e da sexualidade através da divisão do trabalho, da família, do matrimônio e da reprodução."

O sistema de gênero é o sistema simbólico ou o sistema de significados que correlaciona o sexo com conteúdos culturais de acordo com valores e hierarquias sociais. Ele sempre está intimamente conectado em cada sociedade com fatores políticos e econômicos, como afirma Teresa de Lauretis, ${ }^{12}$ o que demonstra a operação de articulação de diversos fatores na produção de vivências sociais legítimas ou abjetas. Para a autora, a construção cultural do sexo no gênero e a assimetria que caracteriza os sistemas de gênero em diversas culturas são entendidas como estando ligadas sistematicamente à organização da desigualdade social. Isso deixa explícito que a produção de gênero integra o processo de domesticação de sujeitos para a socialização em culturas e engendra violências a partir desse mesmo sistema de sexo/gênero, entendido como norma.

Releituras do sistema sexo/gênero serão feitas nos anos posteriores. Marcos Renato Benedetti, ${ }^{13}$ ao analisar a experiência de travestis, destaca uma contribuição importante do feminismo da segunda onda, ao apontar que o gênero deve ser compreendido como uma lógica social que institui significados a corpos, práticas, relações, crenças e valores. Mais do que um fator cultural de diferenciação, 
homens (Amélia VALCÁRCEL, 2000). Observa-se que nesse momento as feministas não procuravam transformar radicalmente as estruturas sociais que sustentavam a manutenção de privilégios por parte dos homens através da opressão e da subordinação das mulheres, mas buscavam ser reconhecidas como cidadãs a partir da concepção liberal do termo, não questionando as caracterizações essencialistas que Ines eram atribuídas. Muitas vezes, elas se valiam dessas como estratégia argumentativa na busca por conquistas de direitos. Essa será uma posição problematizada pela segunda onda do feminismo.

${ }^{10}$ RUBIN, 1975.

1 Ochy CURIEL, 2006.

12 Teresa DE LAURETIS, 1989.

${ }^{13}$ Marcos Renato BENEDETTI, 2005.

14 Joan SCOT, 1995.

${ }^{15}$ Silvania Veleda da SILVA, 2000 , p. 5 .

${ }^{16}$ Claudia de Lima COSTA e Eliane ÁVILA, 2005.

17 SCOTT, 1995.

${ }^{18}$ CURIEL, 2006

${ }^{19}$ COSTA, 1998, p. 129. deve ser entendido como a própria condição da produção de diferenças entre o masculino e o feminino.

O gênero ganhará força nos meios acadêmicos; será utilizado pelas feministas como uma ferramenta para as análises de estruturas sociais na tentativa de rejeitar as explicações biologicistas sobre os elementos que estruturam e fundamentam as desigualdades entre homens e mulheres. É na década de 1980 que o gênero ganha um alcance e uma aceitação mais amplos, fato que possibilitou uma melhor acolhida e legitimidade das feministas dentro de alguns espaços, tais como a academia e instituições governamentais, nas quais as perspectivas feministas tinham sido recebidas, até então, como estridentes. ${ }^{14}$

No Brasil, o feminismo ressurge na década de 1970 em um contexto de autoritarismo e repressão do regime militar no qual as feministas reivindicavam tanto "pela igualdade das mulheres como pela anistia e pela abertura democrática". ${ }^{15}$ Na década de 1980, com a "transição lenta e gradual" do regime militar, partidos políticos saíram da clandestinidade, sendo um forte campo de ação de feministas brasileiras. No processo de reconstrução das instâncias da democracia liberal, as feministas adentraram as instâncias governamentais e tal situação as dividia em relação à proximidade estabelecida entre o movimento e o Estado. O fortalecimento do feminismo no Brasil coincide com a introdução do conceito de gênero no país. Rapidamente, nos anos 1980, disseminou-se o uso do termo "gênero" em diversas instituições do Estado e na academia, tendo maior receptividade nesses campos. Esse período foi marcado também pela "onguização" e pela profissionalização dos movimentos sociais. ${ }^{16}$

A substituição do termo "mulher" (estudos da mulher ou de mulheres) pelo de "gênero" (estudos de gênero) possibilitou a introdução de estudos sobre a mulher em espaços até então tidos como impenetráveis, pois gênero representava certo status e sofisticação às pesquisas, além de ter uma conotação mais objetiva e neutra. ${ }^{17}$ Desse modo, a utilização do conceito "gênero" foi importante para que o tema "mulher" fosse introduzido com maior facilidade pelos discursos oficiais e pudesse denunciar os pressupostos androcêntricos e sexistas das instituições e nas relações sociais, ${ }^{18}$ o que aconteceu no Brasil e também em outros contextos. No entanto, ao longo do tempo, "deixou-se de lado a crítica feminista, a opressão e a subordinação da mulher, diluiu-se e neutralizou-se nos discursos e práticas de tais instituições". ${ }^{19} \mathrm{Na}$ intenção de não nomear algumas noções, tais como homem e mulher, e para evitar posições essencialistas, o que acabou resultando em um "feminismo sem mulheres". A partir desse momento, "podia-se estudar a 
${ }^{20}$ COSTA, 1998, p. 135.

${ }^{21}$ SCOTT, 1995.

${ }^{22}$ COSTA, 1998

${ }^{23}$ Rosi BRAIDOTTI, 1993.

24 Judith BUTLER, 1987 e 1999.

${ }^{25}$ BRAIDOTTI, 2000.

${ }^{26}$ Esta foi interpretada e debatida por diversos autores que utilizaram nomeações e enfoques distintos. Noções como política heterossexual, heteronormatividade e heterossexualidade compulsória revelam algumas das abordagens feitas a partir de uma perspectiva lésbica, dentro do feminismo. opressão da mulher e as relações desiguais sem assumir um projeto político feminista". ${ }^{20}$

Outro ponto que facilitou a entrada do conceito de gênero na academia refere-se ao foco no seu aspecto relacional a partir da não aceitação de uma análise interpretativa de esferas separadas entre homens e mulheres, já que estudálas de forma isolada poderia resultar em criações de mitos como o de que a experiência de um sexo não tem relação com o outro. ${ }^{21}$ Esse aspecto relacional foi um forte facilitador da inserção do gênero no meio acadêmico, uma vez que não possuía a mesma carga reivindicativa que o termo "mulher" trazia naquele momento. Além do mais, permitiu a entrada, cada vez mais crescente, de estudos sobre os homens na academia (estudos das masculinidades), com uma leitura que, de forma recorrente, escapa a uma perspectiva feminista, permitindo afirmar que, no final da década de 1990, o gênero passe a ser interpretado como masculinidade ${ }^{22}$ em campos de conhecimento como a antropologia e a psicologia social, por exemplo. As formas como gênero e seus usos promoveram uma espécie de neutralização das posições feministas não é a única crítica que se fez a essa categoria analítica. A partir da década de 1970, percebe-se um posicionamento de algumas feministas que questionaram a construção e a concepção abstrata em torno da categoria "gênero", desvelando as hierarquias existentes entre as próprias mulheres. Deparamo-nos com um número significativo de teóricas, principalmente as pós-coloniais, as feministas negras e as pensadoras lésbicas, que questionaram o conceito de gênero e apresentaram críticas contundentes a ele, o que permite dizer, tal como afirma Rosi Braidotti, ${ }^{23}$ que a noção de gênero atravessa um momento de crise. Como dizer das opressões e das violências vivenciadas por mulheres negras, pobres e lésbicas, se gênero pretende abarcar uma abstração universalizante do que seja mulher?

No campo da epistemologia, várias críticas foram delineadas. Algumas dessas contribuições foram de Judith Butler, ${ }^{24}$ que argumentará que o feminismo manteve a posição dualista do sexo no gênero (pilar do pensamento falocêntrico), ou de Braidotti, ${ }^{25}$ que apontará que esse fato confina o feminino à posição estrutural de "outro", no qual o homem é universal e tem o direito à transcendência e à subjetividade, enquanto a mulher perde a subjetividade e ocorre o confinamento do seu corpo.

\section{Tensões do gênero: outras vozes}

Outras críticas foram feitas à noção de gênero a partir da introdução do debate do colonialismo, do racismo e da sexualidade ${ }^{26}$ no campo da discussão feminista. Buscamos 
aqui analisar a concepção de sujeito do feminismo de três autoras feministas provenientes de contextos sociais, culturais e políticos distintos, identificando suas posições em relação à categoria "gênero" e diante das hierarquias entre categorias sociais, bem como as consequências dessas concepções para a ação política feminista. São elas: Gloria Anzaldúa, Monique Wittig e Ochy Curiel, sendo que, da primeira e da terceira, tomamos suas críticas às lógicas coloniais como ponto de partida de suas análises e, da segunda, a problematização da posição das lésbicas no feminismo. O que justifica a escolha dessas autoras, dentre tantas outras, é a centralidade da crítica ao gênero a partir de categorias como racismo, colonialismo, política heterossexual que foram analisadas a partir de sua experiência de vida, como teórica e militante. Mesmo que muitas vezes não façam a crítica direta à noção de gênero, 0 pensamento dessas autoras expõem consequências importantes para esse campo teórico-político. Interessa-nos, neste texto, analisar os pontos de ruptura desses pensamentos com a noção de gênero e com os princípios que orientaram a chamada segunda onda do feminismo. Analisar com mais afinco essas rupturas e suas consequências contribui para uma retomada histórica do feminismo que não esteja centrada em uma perspectiva linear e desenvolvimentista da história que frequentemente toma a Europa e os Estados Unidos como referência, mas centrada nos poderes/saberes que foram tensionados, provocando deslocamentos no feminismo. Também não é nossa preocupação aqui partir das classificações já propostas acerca do pensamento dessas autoras em correntes do pensamento ocidental: pósestruturalismo, teoria queer etc. Nosso propósito de análise foca nas rupturas e nas possíveis saídas ou encruzilhadas que colocam para o feminismo.

\section{Experiências que importam: colonialismo, racismo e política heterossexual}

Para alcançarmos o objetivo proposto, escolhemos alguns textos centrais do pensamento das autoras. Não é nossa intenção esgotar a análise de suas contribuições. Como orientadores de nosso trabalho, elencamos quatro elementos analíticos para a leitura do seu pensamento: a concepção de sujeito do feminismo; o posicionamento das autoras em relação à categoria "gênero"; as posições apresentadas pelas autoras diante das hierarquias entre categorias sociais; e suas concepções sobre ação política feminista.

Gloria Evangelina Anzaldúa (1942-2004). Poetisa, escritora e teórica, deixou significativas contribuições para o feminismo, bem como para os estudos pós-coloniais, os 
27 Gloria Evangelina ANZALDÚA, 1987.

${ }^{28}$ ANZALDÚA, 1987. estudos sobre raça e sexualidade, entre outros campos de conhecimento. A sua obra mais conhecida é Borderlands/ La Frontera: The New Mestiza, ${ }^{27}$ sendo essa obra composta de diversos gêneros literários, além de fragmentos de ensaios e canções.

Anzaldúa critica a cultura etnocêntrica e androcêntrica das culturas brancas, indígenas, chicanas, sendo muitas vezes tida como traidora de sua própria terra (da cultura chicana) por não aceitar as histórias e os mitos patriarcais presentes nela. A autora complexifica o olhar sobre as opressões às quais as mulheres são submetidas $e$ invoca outros sistemas simbólicos e mitos em que a experiência da mulher não seja negada. Afirma que "no fui yo quien vendió a mi gente sino ellos a mí". ${ }^{28}$ Pontua que muitas regras sociais, definidas como naturais, são estipuladas com a finalidade de manter hierarquias sociais, como a entre homens e mulheres, em que aqueles possuem o poder da fala em detrimento das mulheres; essas, quando falam, são deslegitimadas e chamadas de hociconas e callejeras ou terão que ouvir, desde meninas: "en boca cerrada no entran moscas".

Diante dessa opressão, Anzaldúa discorre sobre a formação de uma nova consciência, uma consciência mestiza, uma consciência da fronteira. A ideia de fronteira aparece de formas distintas ao longo de seus escritos - a fronteira é geográfica, mas também metafórica. No primeiro aspecto, refere-se às tensões culturais, políticas e econômicas vivenciadas na fronteira entre México e Estados Unidos; fala também de um contexto político e social marcado por opressões e colonização espanhola. No entanto, essa experiência fronteiriça não se reduz a uma estrutura física e fixa, mas se refere a outras fronteiras: de raça, classe, orientação sexual, gênero. Refere-se também às fronteiras rígidas criadas pelo pensamento binário ocidental. Contudo, ao mesmo tempo que essas fronteiras podem indicar limites fixos e totalizantes, o seu cruzamento (dangerous crossroads) é um movimento que evita o aprisionamento - remete ao hibridismo e à fluidez, à possibilidade de transitar entre lugares distintos e com efeitos de poder diversos.

A fronteira é uma metáfora para dizer das experiências múltiplas que perpassam o sujeito, sendo muitas dessas incompatíveis; antagonismos esses que causam intensa dor, mas que podem transformar a própria existência do sujeito e a sua percepção e relação com a "realidade". Para Anzaldúa, a fronteira é um lugar indeterminado, um não lugar, perpassado por opressões e sofrimento. No entanto, abre-se também a possibilidade da invenção, da criatividade, da liberdade, do ilegal, constituindo-se, assim, em espaço de poder e resistência. ${ }^{29}$ Portanto, a fronteira 
${ }^{30}$ ANZALDÚA, 1987.

significa a possibilidade de construção de algo novo, contrapondo-se ao modelo hegemônico cultural ocidental, que não comporta contradições e oposições.

A nova mestiza, como dirá a autora, passa a questionar os padrões culturais, principalmente o branco, 0 androcêntrico e o etnocêntrico, que lhe foram ensinados e impostos, e observa que é impossível continuar a viver em padrões culturais tão limitados. Diante disso, a nova mestiza aprende a transitar entre culturas. Entretanto, isso não significa juntar várias culturas de modo descontextualizado e transformá-las em outra qualquer, mas passar por um processo de conhecimento e apropriação das culturas que a constituem para, assim, começar um trabalho minucioso de elaboração de uma cultura própria, descartando as formas opressivas presentes tanto na cultura indígena, mexicana e branca. Segundo Anzaldúa,

Lo que quiero es contar con las tres culturas - la blanca, la mexicana, la india. Quiero la libertad de poder tallar y cincelar mi propio, cortar la hemorragia con cenizas, modelar mis propios dioses desde mis entrañas. Y si ir a casa me es denegado entonces tendré que levantarme y reclamar mi espacio, creando una nueva cultura una cultura mestiza - con mi propia madera, mis propios ladrillos y argamasa y mi propia arquitectura feminista. ${ }^{30}$

A nova consciência mestiza busca subverter o essencialismo e interromper a relação sujeito/objeto, ou seja, o binarismo ocidental, que polariza as existências, tais como mulher $x$ homem; natureza x cultura; preto x branco; Ocidente $x$ Oriente etc., criando hierarquias sociais e legitimando opressões. Dito de outra forma, propõe desconstruir a dicotomia presente no pensamento científico ocidental que separa e hierarquiza a experiência social. Assim, Anzaldúa questiona as certezas epistemológicas do conhecimento científico ocidental e propõe outras epistemologias, tal como o conhecimento da fronteira.

A tradução seria, segundo Anzaldúa, a condição para a existência de diversas culturas. Porém, a tradução não será compreendida por essa pensadora como mera transmissão artificial e mecânica, tal como está presente na cultura ocidental. A tradução, para ela, promove um novo sentido, o qual abre caminho para uma multiplicidade de vozes e incorporações de culturas, possibilitando uma hibridização/ mestiçagem cultural. Para a autora, a leitura da mestiçagem se dá a partir de um exercício de historicização da realidade e da explicitação das relações de poder que marcam e determinam as diversas formas de opressão. Dessa forma, quer tirar da marginalidade experiências e práticas culturais das mulheres de cor que estão desautorizadas a falar; instituídas como vozes subalternizadas e colonizadas. 
${ }^{31}$ COSTA e ÁVILA, 2005.

\footnotetext{
32 Luce IRIGARAY, 1985.
}

Assim, defende a posição de que as mulheres de cor devem buscar meios de expressar as suas ideias, deixando de ser objeto de estudos para ocuparem lugares de fala, e as convoca a falar, pois, além de denunciar a opressão, podem colocar em disputa a construção de sistemas de significados e de subjetivação que contrapõem o sistema dominante, possibilitando, assim, a criação de novas culturas e novas consciências. Para a autora, escrever é um ato de resistência, capaz de transmitir a experiência da fronteira. O posicionamento perante a linguagem também expressa um caráter político; a língua expressa resistência. Por isso defende a resistência da língua fronteiriça, que não ceda à língua do colonizador, defendendo a permanência da língua selvagem.

Anzaldúa trouxe para o feminismo questões relevantes ao apresentar vozes dissonantes com o feminismo tido como hegemônico nas décadas de 1970/1980, isto é, defendeu a intervenção de mulheres feministas de cor, lésbicas, mulheres de Terceiro Mundo contra a miopia das mulheres brancas, anglófonas, heterossexuais, protestantes e de classe média. ${ }^{31}$ Nesse movimento de explicitar outras vozes feministas, Anzaldúa propõe um movimento de descolonização para que as mulheres do Terceiro Mundo produzam o seu próprio conhecimento e busca desvelar a posição subalternizada da mulher a partir do cruzamento entre raça, sexualidade e gênero. Assim, para além da dicotomia de gênero, ela questiona as hierarquias existentes entre as próprias mulheres em relação à raça, sexualidade, classe, já que a categoria "gênero" é limitada e não engloba todas as subordinações presentes no campo social.

Monique Wittig (1935-2003). Escritora, poeta e crítica literária, com atuação bastante relevante no movimento feminista francês do século XX, considerava-se uma lésbica radical, ligada à tendência materialista do feminismo francês. Seus escritos indicam o interesse em superar a noção de gênero e de heterossexualidade. Causou grande polêmica ao defender a posição de que as "lésbicas não são mulheres", apresentada em sua palestra "O pensamento heterossexual", proferida em 1978 durante a conferência anual da Associação da Linguagem Moderna em Nova York.

A produção da autora se deu em um momento do feminismo francês no qual estavam em voga concepções teóricas ligadas ao feminismo da diferença. Uma das representantes dessa corrente, Luce Irigaray, ${ }^{32}$ feminista e psicanalista, defende que não se deve lutar por uma igualdade entre os sexos quando essa significar a supressão das diferenças entre mulheres e homens, mas deve-se empregar uma luta que colabore para a valorização das diferenças sexuais. Irigaray direciona suas críticas em 
${ }^{33}$ Monique WITTIG, 2006.

${ }^{34}$ Louise TURCOTTE, 1992.

${ }^{35}$ WITTIG, 2006.

grande medida para a psicanálise, devido ao machismo presente nas teorias fundantes desse arcabouço teórico, criticando a normatização que a primazia da subjetividade masculina impõe ao mundo. Propõe que a criação de uma cultura de valorização dos dois sexos deve primar pelo respeito das peculiaridades das subjetividades masculina e feminina, mas aponta que essas não devem seguir prescrições absolutas de existência, devendo haver espaço para diferentes "nuances" do que seja o feminino e o masculino.

Monique Wittig ${ }^{33}$ se contrapõe de forma radical a essa perspectiva, ao defender que a solução para a opressão das mulheres não será alcançada através de uma educação para a diferença e do reconhecimento das diferenças entre os sexos e igual valorização, mas sim por meio da explicitação do antagonismo existente entre as diferentes posições sociais ocupadas por homens e mulheres através de relações assimétricas de poder. As argumentações a favor de uma convivência inclusiva entre os dois sexos muitas vezes (re)produzem as próprias exclusões que pretendem sanar, podendo contribuir para a criação de um discurso da tolerância que não elimina a hierarquia tolerante $x$ tolerado, reforçando assim uma inclusão subalterna que não rompe com a relação de servidão.

Para a autora, paradoxalmente, as mulheres devem se constituir como classe sexual oprimida por uma política heterossexual (condição necessária à opressão masculina) para que essa mesma condição de oprimida possa deixar de existir. A política heterossexual oprime porque define as mulheres a partir dos homens (masculino universal/feminino particular) e de relações de servidão e dependência econômica, social e emocional delas para com os homens, lugar físico/simbólico e material, meio de produção dos opressores, no qual a mulher se torna meio de manutenção da ordem social androcêntrica e, consequentemente, da supremacia social masculina.

Segundo Louise Turcotte,,$^{34}$ esse deslocamento do movimento feminista permite que se façam críticas a um ponto que até então não havia sido radicalmente criticado: a heterossexualidade. Wittig concebe esse mecanismo como algo que se refere a um regime político que serve à manutenção da hierarquia entre homens e mulheres e que pressupõe uma relação de dependência econômica, emocional e social delas, o que reforça um ideal burguês de reprodução familiar. Se a ideia da família é a reprodução, então as mulheres podem ser reduzidas a fêmeas parideiras, sendo excluídas do rol de humanidade.

Romper com a condição imposta através da política heterossexual se torna crucial para que as mulheres possam se organizar de forma autônoma, e, segundo Wittig, ${ }^{35}$ a lésbica 
${ }^{36}$ WITTIG, 2006. política é o sujeito político capaz de romper com essa relação de servidão/escravidão material e simbólica. Propõe a desnaturalização do sexo, já que consiste em um construto social, e não uma essência biológica, possibilitando, dessa maneira, a emergência da lesbianidade política, entendida como posicionamento das mulheres de recusa dos homens e da constituição social.

Diante disso, a lésbica, para Wittig, não seria somente uma identidade constituída única e exclusivamente a partir de práticas sexuais, mas sim uma identidade política que visa ao fim das relações heterossexuais compulsórias. Como dissolução da opressão sexual, Wittig propõe que as mulheres reconheçam os mecanismos e os recursos materiais/tecnocientíficos/simbólicos que formam as bases dessa mesma opressão e então possam se articular como classe e lutar pela abolição da ordem social sexista, fazendo com que o conceito social de sexo - e também a noção de mulher deixe de existir.

A luta de classes desmantela as próprias classes no momento em que as constitui e as mostra como classe, ou seja, desconstrói a suposta naturalização da opressão e, assim, problematiza-a, historiciza-a, possibilitando que as classes sejam destruídas. ${ }^{36} \mathrm{~A}$ articulação necessária para que se possa passar do entendimento de grupo social subordinado (inferiorização naturalizada) ao de grupo oprimido (politização e desnaturalização da realidade) é crucial para que se possam explicitar as relações de disputa e manutenção de poder que envolvem a construção social do sexo, denunciando seu caráter de oposição.

A ideia de constituição relacional entre homens e mulheres só é possível através do mecanismo da heterossexualidade, portanto o gênero não desconstrói a economia heterossexual. Wittig defende que o conceito de lésbicas políticas é o que permite o enfrentamento radical da heteronormatividade, pois rompe com a relação de servidão obrigatória das mulheres. Tal conceito aparece como crítica à naturalização das categorias "homem" e "mulher", pois essas são constituídas a partir de uma relação análoga à de "senhor-escravo" e se configuram como identidade política que proporciona a solidariedade entre as mulheres e a unificação delas na luta por emancipação. Para a autora, as lésbicas não podem ser consideradas mulheres, pois se recusam a fazer parte da relação de escravidão que constitui a relação heterossexual e as categorias sexuais. Essa é a ideia que fundamenta a proposta de que as mulheres devem se unificar e se constituir como classe oprimida para a luta contra essa opressão propiciada por meio da criação das atribuições sociais da mulher. As lésbicas recusariam, portanto, a categoria "mulher". 
${ }^{37}$ WITTIG, 2006.

Para a autora, o termo "gênero" não dessencializa a heterossexualidade pois não explicita a construção social da categoria "sexo", mantendo assim a ideia de diferença e complementariedade sexual. Essa opera de modo a censurar/ocultar a oposição que existe no plano social entre homens e mulheres, apontando para a "constituição natural dos sexos" como causa das dicotomias. Essa naturalização dissimula o fato de que desigualdades sociais implicam sempre manutenção de uma ordem econômica, política e ideológica que pressupõe, por sua vez, divisões no plano material e econômico.

O gênero, portanto, despolitiza o sexo - ou seja, a opressão sexual que o constitui -, ao continuar tratando, até mesmo linguisticamente, o masculino como o universal de humanidade, enquanto a mulher é generificada e sexualizada, sendo tomada como o particular, a exceção, o "caso à parte", a diferença, enquanto o homem, o masculino, continua sendo o universal neutro, a origem e o objetivo de toda construção histórica.

Wittig,,$^{37}$ ao defender que a construção social do sexo é feita através de uma relação de dominação na qual um sexo oprime e outro é oprimido, denuncia que é a própria opressão que cria o sexo, e não o contrário. Se considerássemos que o sexo biológico é a base propiciadora da opressão (como causa), então essa justificar-se-ia a partir da naturalização da posição de desigualdade.

Ochy Curiel (1963). Nascida na República Dominicana, morou no Brasil, no México e na Argentina e, atualmente, reside na Colômbia. Licenciada em Serviço Social, com especialização em Antropologia Social, é pesquisadora e ativista do movimento lésbico-feminista latino-americano e caribenho. Ao longo da sua pesquisa e produção bibliográfica, assim como de seu ativismo, trabalha em profundidade o campo das identidades, suas configurações, capacidades e potencialidades em relação à emancipação, principalmente, de feministas lésbicas, negras e indígenas. Esse processo de análise é construído e sustentado no diálogo com as produções do feminismo negro, feminismo do Terceiro Mundo, feminismo pós-colonial e feminismo chicano, que não chegaram a ser totalmente reconhecidos pela academia nem pelo feminismo liberal, nem pelos grandes críticos póscoloniais. São esses feminismos, segundo Curiel, que têm construído uma contundente crítica a partir da interseção entre o sexismo, o classismo e o racismo, com foco no capitalismo como sistema de dominação e colonialidade atual. Nesse sentido, aparece nas suas produções uma crítica ao gênero baseada nas limitações dessa categoria para tencionar os eixos que atravessam a construção social do gênero, como a classe, a raça e a política heterossexual. 
${ }^{38}$ Betty FRIEDAN, 1963.

${ }^{39}$ Sueli CARNEIRO, 2003.

${ }^{40}$ CURIEL, 2002.
Com base em um posicionamento lésbico-afrodescendente, a autora faz um mapeamento dos diferentes usos das identidades, especialmente nos movimentos feministas de mulheres negras e lésbicas. Num primeiro momento, a autora se distancia contundentemente do uso essencialista e biologicista das identidades, apoiada na tarefa, realizada com outras feministas durante décadas, de visibilizar e conceber a raça, o gênero e a heterossexualidade como construções sociais, dispositivos de poder e subordinação. Por outro lado, entendendo a situação de conflito existente e como as diferentes hierarquias apresentam consequências diretas na vida das mulheres negras ao longo da história e na atualidade, Curiel indaga também acerca do uso "político das identidades". Faz uma análise dos fatores que possibilitam sua emergência, das distintas formas e desenhos das identidades, bem como sua potencialidade no contexto da prática política.

Curiel realiza críticas a outras feministas como Betty Friedan e sua obra The Feminine Mystique, ${ }^{38}$ que se converteu em grande referencial teórico para as feministas norteamericanas da segunda onda do feminismo. Friedan vai construir uma proposta de emancipação feminista em que as mulheres deveriam desprender-se do trabalho doméstico e buscar a profissionalização, tal como faziam os homens. Nesse ponto, Curiel, dialogando com o feminismo negro, avaliará tal proposta, assim como outras pensadoras do feminismo negro, como classista e racista, já que Friedan não contemplou, no seu ideal de libertação da mulher, "as mulheres afrodescendentes, que sempre trabalharam fora do âmbito doméstico como força de trabalho nas ruas e nas casas dos brancos e brancas, como conseqüência da escravidão". ${ }^{39}$ Curiel identifica a perspectiva de gênero como insuficiente para compreender como o sexismo afeta as mulheres, uma vez que tem grande limitação para enxergar as diferentes formas de subordinação que surgem e se articulam na transversalidade de eixos, como raça, classe e heterossexualidade obrigatória.

Com base na identificação dessa invisibilidade e/ou invisibilização das mulheres negras nos trabalhos provenientes das acadêmicas norte-americanas e europeias, a autora destaca o "risco" de se esquecer da diferença a partir da criação de uma falsa homogeneidade em que os grupos privilegiados esquecem-se de sua própria especificidade. ${ }^{40}$ E é nesse ponto que a identidade se apresenta não como um pressuposto essencial, mas sim como a lembrança de uma convivência não harmônica em que os sujeitos agem e se articulam perante uma cultura que está sendo massacrada, na tentativa de sair do lugar de outro e de se posicionar diante de um feminismo que não questiona a "diversidade" 
${ }^{41}$ CURIEL, 2009a.

${ }^{42}$ CURIEL, 2002, p. 3-4.

${ }^{43}$ CURIEL, 2002, p. 5.

${ }^{44}$ CURIEL, 2003, [s.p.]. do sujeito, que não distingue diferença de desigualdade. 0 uso da identidade se transforma, portanto, em uma estratégia de ação política para a desarticulação do dispositivo racista, e não como a configuração de um sujeito homogêneo. ${ }^{41}$ Fazendo uso da própria experiência, Curiel traz o ato de nomear-se "orgulhosamente negra" como uma forma de gerar sentido de pertencimento entre semelhantes, de nomear e visibilizar as desigualdades e até como prática de sobrevivência e reafirmação para, assim, (re)construir um lugar na história como um produto das relações sociais que se produzem e reproduzem diariamente. Para a autora, a política da identidade é estratégica e tem, sim, suas vantagens, mas, dependendo da configuração e do uso dessa identidade, pode representar um problema para a prática política: "Ciertamente esto condujo a un autoreconocimiento y un aumento de la autoestima de muchas de nosotras. El problema es que no hemos ido más allá". ${ }^{42}$

Ela pergunta se realmente é necessária uma identidade comum para o feminismo, sendo que essa invisibilizaria a diversidade interna. Segundo a autora, o sujeito feminista deve configurar-se na ação de combate à opressão sexista a partir de diferentes lugares, corpos e histórias, entendendo que o sexismo é um sistema de subordinação atravessado e articulado necessariamente com o racismo, o classismo e a heterossexualidade obrigatória. Nesse sentido, a proposta é um sujeito que não estaria baseado em uma identidade que predetermina uma união e semelhança a priori, mas sim no fato de compartilhamento de uma experiência histórica e cotidiana de opressão e de um sonho comum da emancipação.

Creo que es más importante ser antirracista que orgullosamente negra, creo que es más importante ser feminista que reconocernos mujeres, creo que es más importante eliminar el régimen de la heterosexualidad, que ser lesbiana, creo que lo importante son los proyectos políticos de transformación $[\ldots]^{43}$

Se, por um lado, pode-se considerar uma estratégia problematizar as identidades, tal como a citação nos indica, para ir além da crítica e dar visibilidade a um mecanismo de poder que é mais complexo que a cor ou a orientação sexual, por outro, é necessário tomar cuidado com que as críticas à identidade transformem-se em uma ferramenta das elites feministas acadêmicas para deslegitimar novamente as estratégias de confronto e visibilidade por parte de feministas negras e lésbicas no interior da luta das mulheres. Curiel sintetiza essa posição afirmando: "Olvídate de que soy negra, pero nunca te olvides de que soy negra". ${ }^{44}$

Curiel analisa ainda como grande parte da população negra na América Latina e no Caribe tem sua história 
${ }^{45}$ CURIEL, 2007 e 2009b.

${ }^{46}$ Outro ponto importante colocado pela autora no caminho a um feminismo descolonizado é a necessidade de uma luta das mulheres que não dependa do Estado nem das políticas institucionais, especialmente nesse momento em que se evidenciou sua tarefa de expropriar terras de povos indígenas e afrodescendentes para fins lucrativos, precarizando a vida de milhares de negros/negras, principalmente das mulheres negras. É preciso reconhecer o discurso sobre democracia racial e mestiçagem como um dispositivo de poder racista, inclusive para apontar as migrações mundiais e novas (e não tão novas) formas de escravidão e visibilizar suas principais vítimas e responsáveis/ benfeitores diretos ou indiretos. passada relacionada com a África e com o processo de escravidão, embora a ideologia dominante não tenha mostrado essa história. Diante disso, destaca a necessidade de conhecimento dessa história, o que possibilitaria que sujeitos se reconhecessem como aqueles que compartilham uma experiência histórica de colonização comum e que possui efeitos nas vidas de homens e mulheres negras na atualidade. Aponta como prática de transformação dessa realidade a descolonização, ${ }^{45}$ dando especial destaque à necessidade de uma descolonização acadêmica nas instituições de ensino e de produção de conhecimento que deveriam, segundo a autora, cumprir a tarefa social e políica de fornecer ferramentas teóricas, metodológicas, epistemológicas e políticas à população e aos movimentos para analisar criticamente sua condição de opressão e construir possibilidades de enfrentá-la. A divisão entre conhecimento puro (objetivo/teórico) x conhecimento "ideologicamente" contaminado (ativismo político/prático) constitui, para Curiel, uma prova da relação poder-conhecimento e faz a crítica à teoria feminista latino-americana por não ter se descolonizado, já que feministas acadêmicas da região raramente utilizam autoras latino-americanas ou do "Terceiro Mundo" para fundamentar suas produções. Identifica-se no seu lugar uma ampla bibliografia de autoras europeias e norte-americanas, não havendo uma genealogia intelectual que analise os modos com que a produção de um discurso feminista "do norte" tem deslegitimado o feminismo latino-americano.

Assim, é necessário construir um feminismo que não se pretenda universal/universalizante, mas sim que reconheça os diferentes feminismos, especialmente aqueles que não nasceram com a Revolução Francesa. É preciso assumir uma postura de compromisso que conte as diferentes histórias do feminismo que pouco ou nunca foram contadas, criando uma oposição ao feminismo ilustrado, branco, heterossexual, institucional e estatal ${ }^{46}$ e possibilitando a construção de uma prática política radical que não permita que a categoria "gênero" continue sendo utilizada para despolitizar a luta das mulheres.

A luta política, como já foi apontado antes, deve possibilitar a nomeação da opressão e combatê-la, criando solidariedade entre aquelas e aqueles que vivenciam situações de subordinação. É preciso uma mestiçagem geradora de novas relações que considere a diversidade sem ser baseada em privilégios nem exploração e que incorpore, obrigatoriamente, a perspectiva feminista em todo o agir humano, não como discurso, mas sim como meio para a eliminação da desigualdade entre os sexos: "Todas estas propuestas, la de las afrodescendientes, las de las multiculturalistas, las de las lesbianas feministas, las postcolonialistas, las materialistas, nos ofrecen visiones feministas más amplias 
${ }^{47}$ CURIEL, 2006, [s.p.].

48 Ver: "Ain'† I a Woman", de Soujourner Truth, proferida em 1851 na Conferência das Mulheres em Ohio/EUA. que solo pararse desde el género como perspectiva política". ${ }^{47}$

\section{Feminismo no plural}

Ao longo do nosso percurso, buscamos centrar o olhar nos pontos de tensão, de deslocamento e de rupturas que críticas à noção de gênero, produzidas a partir de problematizações do racismo, do colonialismo e da sexualidade, têm promovido dentro do feminismo. É importante destacar que várias autoras fizeram críticas à noção de gênero e, mesmo quando essa categoria não havia sido relida pelo feminismo, encontram-se reflexões - no campo da teoria e da luta políitica - sobre a ausência de determinadas mulheres das causas feministas ${ }^{48}$ Escolhemos três autoras que avaliamos como expressões representativas dessas críticas (mas não únicas), de contextos tão distintos, que se opuseram ou problematizaram dinâmicas de poder que subalternizam mulheres através de processos e com efeitos semelhantes. Frequentemente, na luta política feminista atual, somos convocadas a considerar as especificidades e as diferenças das mulheres. Contudo, essa tarefa não é nada simples. Um caminho que propomos para enfrentar esse desafio é analisar, com o cuidado e a profundidade que o problema em questão exige, como essas categorias emergiram no feminismo, que antagonismos provocaram, que relações de poder revelaram. É importante identificar e compreender as tensões causadas para que conexões, articulações e interseções sejam promovidas na luta e na teoria feministas sem a prescrição de um sujeito único. Por isso escolhemos analisar três contribuições que revelam, em nossa avaliação, possibilidade de equivalência entre si.

Sobre o sujeito do feminismo, vimos que Anzaldúa, Wittig e Curiel problematizam a pretensa universalidade pela qual gênero foi se configurando e denunciam os efeitos normativos e de invisibilidade em relação às experiências de mulheres negras, lésbicas e do Terceiro Mundo. Baseadas nas noções de fronteira, de lesbianidade como posição política e de identidade como antagonismo, convocam, de distintas formas, a politização da relação entre mulheres no interior do feminismo. Nesse sentido, o sujeito do feminismo passa a ser uma construção marcada por tensões e (re)configurações constantes, já que não se delimitaria a partir de uma posição a priori, mas seria marcado pelas contingências da luta e dos antagonismos políticos. As três empenhar-se-ão em denunciar o efeito hierarquizante e normativo que o gênero teve no feminismo, embora reconheçam a importância do combate ao sexismo. A diferença é que, ao problematizarem a pretensão universalista do 
gênero, vão indicar a necessidade de uma análise crítica acerca de outros sistemas de opressão e seus efeitos normativos sobre as mulheres, como o colonialismo, o racismo, a política heterossexual. Sobre as hierarquias sociais, a partir de seus lugares como teóricas e ativistas, interpretam relações de subordinação como relações de opressão através de um movimento de desnaturalização e consequente politização da relação entre as mulheres: não tomam as diferenças entre mulheres brancas heterossexuais e negras e lésbicas como algo natural, mas como efeito de relações de poder que são produzidas por diversos sistemas de opressão. Dessa forma, uma contribuição importante da aproximação entre essas perspectivas aponta para a noção de um sujeito do feminismo que tem a correlação e a interseção, e não a neutralização, das diversas posições de poder vivenciadas pelas mulheres como elemento de reflexão contínuo.

Quanto à ação política feminista pensada por essas autoras, vimos a forte relação com outros aspectos que a história do feminismo já havia indicado: a necessidade da voz própria, de ser sujeito e não objeto da fala, das relações e da sociedade é algo que o feminismo tem problematizado continuamente e que também está presente no pensamento de Anzaldúa, Wittig e Ochy. Contudo, como fruto da crítica que realizam à noção de gênero e ao denunciarem a hierarquização entre mulheres dentro do próprio feminismo, indicando os efeitos heteronormativos e também racistas e coloniais do gênero, identificam que a ação política da reconstrução da fronteira ou da tomada da categoria "mulheres" como classe a ser superada, ou ainda, a descolonização do próprio feminismo é uma tarefa complexa e contínua, mas que deve ser enfrentada. A ação feminista se dirige a problematizar relações de poder que operam no sentido de oprimir, invisibilizar e deslegitimar determinadas experiências e, portanto, exige um movimento de reflexividade contínuo, isto é, de tomar a si mesmo e ao feminismo como objetos de reflexão e desconstrução. Assim, é importante problematizar o gênero, reconhecendo e valorizando todas as conquistas que possibilitou ao feminismo, mas é necessário reconhecer as limitações da categoria, fazendo com que conviva com outras formas de análise e luta. Fazer do feminismo uma posição e ação plurais não é um exercício simples e que se reduz à retórica do "vamos incluir todas as mulheres". É preciso problematizar e analisar quais dinâmicas de poder separam as mulheres e colocam, em disputa, a (re)construção de um projeto feminista. O feminismo possibilitou a politização da sociedade ao desnaturalizar relações de poder que determinam a vida das mulheres na vida privada e pública, nas diversas instituições baseadas em subordinação compreendida como natural; é necessário 
também desnaturalizar e constantemente politizar o próprio feminismo.

\section{Referências}

ANZALDÚA, Gloria Evangelina. Borderlands/La Frontera: The New Mestiza. San Francisco: Spinsters/Aunt Lute Books, 1987.

BEAUVOIR, Simone de. El segundo sexo. Buenos Aires: Siglo $\mathrm{XX}, 1972$.

BENEDETTI, Marcos Renato. Toda feita: o corpo e o gênero das travestis. Rio de Janeiro: Garamond, 2005.

BRAIDOTTI, Rosi. "Gender and Post-Gender: The Future of an Illusion." Quaderni dei Nuovi Annali, n. 31, p. 51-69, 1993. . Sujetos nómades: corporización y diferencia sexual en la teoría feminista contemporánea. Buenos Aires: Paidós, 2000.

BUTLER, Judith. "Variações sobre sexo e gênero: Beauvoir, Wittig e Foucault”. In: BENHABIB, Sheila; CORNELL, Drucilla (Org.). Feminismo como crítica da modernidade. Rio de Janeiro: Rosa dos Tempos, 1987. p. 139-154.

. "Corpos que pesam: sobre os limites discursivos do sexo". In: LOURO, Guacira Lopes (Org.). O corpo educado: pedagogias da sexualidade. Belo Horizonte: Autêntica, 1999. p. 151-174.

CARNEIRO, Sueli. "Enegrecer o feminismo: a situação da muIher negra na América Latina a partir de uma perspectiva de gênero". In: ASHOKA EMPREENDIMENTOS SOCIAIS; TAKANO CIDADANIA (Org.). Racismos contemporâneos. Rio de Janeiro: Takano Editora, 2003.

COSTA, Ana Alice Alcântara. "O movimento feminista no Brasil: dinâmicas de uma intervenção política". Niterói, v. 5, n. 2, p. 9-35, 1. sem. 2005.

COSTA, Claudia de Lima. "O tráfico do gênero". Cadernos Pagu, n. 11, p. 127-140, 1998.

COSTA, Claudia de Lima; ÁVILA, Eliane. "Glória Anzaldúa, a consciência mestiza e o feminismo da diferença". Revista Estudos Feministas, Florianópolis, v. 13, n. 3, p. 691-703, set./dez. 2005.

CURIEL, Ochy. Una (auto)critica ante nuestras luchas políticas de cara al racismo. fev. 2002. Disponível em: <http:// webs.uvigo.es/pmayobre/master/textos/maria_jimenez/ autocritica_racismo.pdf > . Acesso em: 23 set. 2011. . "La lucha política desde las mujeres". In:

Red de mujeres afrolatinoamericanas y afrocaribeñas: aproximación al análisis de estrategias frente al racismo. 2003. Disponível em: <http://movimientos.org/es/ mujerafro >. Acesso em: 23 set. 2011. 
. "Los limites del género en la práctica política feminista y las visiones académicas". In: EL GÉNERO: ¿UNA CATEGORÍA ÚTIL PARA LAS CIENCIAS SOCIALES? 2006, Bogotá: Escuela de Estudios de Género y el Centro de Estudios Sociales de la Universidad Nacional de Colombia. . "La crítica poscolonial desde las prácticas políticas del feminismo, antirracista". Revista Nomadas, Bogotá: Instituto de Estudios Sociales Contemporáneos, Universidad Central, n. 26, p. 92-101, 2007.

" "Identidades esencialistas o construcción de identidades políticas: el dilema de las feministas negras". Revista Cultura Electrónica, Lima, Perú, año 5, n. 5, [s.p], nov. 2009 a.

."Descolonizando el feminismo: una perspectiva desde

America Latina y el Caribe". In: PRIMER COLOQUIO LATINOAMERICANO SOBRE PRAXIS Y PENSAMIENTO FEMINISTA, 2009b, Buenos Aires.

DE LAURETIS, Teresa. Technologies of Gender: Essays on Theory, Film and Fiction. London: Macmillan Press, 1989.

FRIEDAN, Betty. The Feminine Mystique. New York: W. W. Norton, 1963.

IRIGARAY, Luce. The Sex which is not one. New York: Cornell Univ. Press, 1985.

MATOS, Marlise. "Movimento e teoria feminista: é possível reconstruir a teoria feminista a partir do sul global?". Revista de Sociologia e Política, Curitiba, v. 18, n. 36, p. 67-92, jun. 2010.

MAYORGA, Claudia; PRADO, Marco Aurélio Máximo. "Democracia, instituição e a articulação de categorias sociais". In: MAYORGA, Claudia (Org.). Universidade cindida, universidade em conexão: ensaios sobre democratização da universidade. Belo Horizonte: UFMG, 2010. p. 46-70.

MEAD, Margaret. Sex and Temperament in Three Primitive Societies. New York: Perennial Classics, 2001.

MIYARES, Alicia. "1848: El manifiesto de 'Seneca Falls"'. Revista Leviatan, Madrid, n. 75, p. 135-158, primavera 1999.

$\mathrm{RICH}$, Adrienne. "Compulsory Heterosexuality and Lesbian Existence." Signs: Journal of Women in Culture and Society, n. 5, p. 631-360, 1980.

RUBIN, Gayle. "The Traffic in Women: Notes on the Political Economy of Sex." In: REITER, Rayna (Ed.). Toward an Anthropology of Women. New York: Monthly Review Press, 1975. p. 157-210.

SCOT, Joan. "Gênero: uma categoria útil para a análise histórica". Educ. e Realid., v. 20, n. 2, p. 71-100, 1995.

SILVA, Silvania Veleda da. "Os estudos de gênero no Brasil: algumas considerações". Revista Bibliográfica de Geografía y Ciencias Sociales, Universidad de Barcelona, n. 262, [s.p.], 15 nov. 2000. 
STOLLER, Robert. Sex and Gender. New York: Science House, 1968.

TURCOTE, Louise. "Foreword." In: WITTIG, Monique. The Straight Mind and Other Essays. Boston: Beacon Press, 1992.

VALCÁRCEL, Amelia. "La memoria colectiva y los retos del feminismo". In: . Los desafíos del feminismo ante el siglo XXI. Sevilla: Instituto Andaluz de la Mujer, 2000. p. 19-54.

WITIG, Monique. El pensamiento heterosexual y otros ensayos. Madrid: Egales, 2006.

WOLLSTONECRAFT, Mary. A Vindication of the Rigths of Woman. New York: The Modern Library, 2001.

[Recebido em 12 de janeiro de 2012,

reapresentado em 18 de abril de 2012 e aceito para publicação em 4 de junho de 2012]

Criticism of the Gender and the Pluralization of Feminism: Colonialism, Racism and Straight Political

Abstract: This article examines the emergence of feminism in specific categories - colonialism, racism and straight political - focusing on aspects that challenge and question the following concept of gender. Interests us here identify contributions these categories have to think about the subjects of feminism and feminist political action. To this end, we propose a brief resume of the historical notion of gender in feminism and analyze the thought of three authors - Gloria Anzaldúa, Monique Wittig and Ochy Curiel - who to include in their analysis of women and society the perspective of colonialism, racism and straight political, sought to clarify the boundaries of the gender, among them, their normative purposes indicates the need for politicizing of feminism. Key Words: Gender; Racism; Straight Political; Colonialism. 